\title{
Virtues in Clinical Practice: Teaching Students about the Complexities and Depth of Professional Practice
}

\author{
Sandra Grace ${ }^{1}$, Airdre Grant ${ }^{2}$ \\ ${ }^{1}$ School of Health and Human Sciences, Southern Cross University, Lismore, Australia \\ ${ }^{2}$ Centre for Teaching and Learning, Southern Cross University, Lismore, Australia \\ Email: sandra.grace@scu.edu.au, airdre.grant@scu.edu.au
}

How to cite this paper: Grace, S., \& Grant, A. (2017). Virtues in Clinical Practice: Teaching Students about the Complexities and Depth of Professional Practice. Creative Education, 8, 2124-2133. https://doi.org/10.4236/ce.2017.813143

Received: September 8, 2017

Accepted: October 22, 2017

Published: October 25, 2017

Copyright $\odot 2017$ by authors and Scientific Research Publishing Inc. This work is licensed under the Creative Commons Attribution International License (CC BY 4.0).

http://creativecommons.org/licenses/by/4.0/

\section{c) (i) Open Access}

\begin{abstract}
This paper investigates the integration of virtues into teaching programs for allied health students. It explores the notion that practitioners' effectiveness is enhanced when they practice virtues along with their technical expertise. These virtues include wisdom and love and they imbue the practitioner's role with a meaning that extends beyond efficient diagnosis and competent case management. Practicing virtues can deepen the clinical relationship. Allied health students may feel cautious and uncertain about what it actually means to be a virtuous practitioner. Reflexive practice and dialogic encounters are presented as teaching activities that can cultivate virtuous practice.
\end{abstract}

\section{Keywords}

Virtuous Practice, Allied Health, Clinical Practice Pedagogy, Wise Practice, Agape

\section{The Contexts of Clinical Practice}

A 50 year old woman visits an allied health student clinic. The young male student assesses her and begins treatment after discussion with the supervisor. The woman indicates she has pain in her knee, and asks the practitioner to go easy. He adjusts the treatment slightly and continues but the treatment still causes her pain. The woman becomes increasingly quiet, then asks the student to stop the treatment and leaves, visibly distressed. The student practitioner is dismayed and doesn't understand her response. His treatment was technically correct for the condition.

Clinical practice is dynamic, relational, and emotionally charged. It inhabits a 
number of contexts including that of the client, the practitioner and the therapeutic encounter (McEldowney \& Connor, 2011). The client's context includes their perspectives on health and illness, practitioners and therapeutic encounters. It includes their bodily experience of health and illness, the effect that their condition has on their family, friends and co-workers, the trust that clients place in their practitioners or services, and their response to a practitioner's willingness to listen and to make them the focus of their attention. In client-centred care, clients are acknowledged as experts in their own illness experiences and their perspectives are highly valued.

The practitioner's context includes their recognition of their personal strengths and weaknesses, the extent of their professional expertise, their previous clinical experience, and the role of their profession in the health care system. Each practitioner's context is unique and evolving. Health practitioners routinely make clinical decisions that affect the safety and wellbeing of their clients and are accordingly encouraged to discuss and negotiate treatment options and likely outcomes with them. When health practitioners gather data about clients, analyse that data, and develop working diagnoses, they draw on a range of strategies that they have developed to deal with the problems they encounter in their daily practices. Some problems require a technical and rational approach while others, the 'messy confusing problems which deny technical solutions' (Schön, 1987: 3), require a blend of biomedical, psychosocial and professional craft, personal knowledge and diagnostic, teaching, negotiating, listening and counselling skills (Jones \& Rivett, 2004).

A third context of clinical practice is the therapeutic encounter, which includes all aspects of the therapeutic intervention, the clinical practice environment, and the relationship between the client and the practitioner. The encounter between client and practitioner is many faceted and replete with the complexity of any human relationship. Its complexity increases when the encounter involves therapeutic touch. A key concept in all definitions of therapeutic touch is the notion of authentic compassionate intent to alleviate pain or illness. Krieger (1992) described therapeutic touch as a direct process of energy exchange during which the practitioner uses their hands as a focus for facilitating healing. It has also been described as the process of touching the 'sick' area and in this way helping the patient to be in better contact with the tissues of their body (Morad, Merrick, \& Ventegodt, 2004).

All three contexts can be enriched if clinical practice is enacted with wisdom and love, including that of the practitioner: practitioners who are willing to be emotionally moved by their clients 'enrich their own experience of doctoring' (Halpern, 2003: 673). In the vignette above, the student had developed the technical expertise to perform clinical skills that were appropriate for the presenting condition, but he failed to read the patient's response to pain during his treatment and her growing disengagement. Students need to develop virtues like wisdom and love, along with technical expertise, in order to provide quality health care (Marcum, 2011). 


\section{What Does It Mean to Be a Virtuous Practitioner?}

Two virtues in particular imbue the role of the practitioner with a meaning that combines all these capabilities and extends beyond efficient diagnosis and competent case management. These are wisdom and love.

\subsection{Wisdom}

Barnett (1997) drew our attention to the wider social responsibilities associated with clinical practice and encouraged practitioners to carry out wise actions not only within the confines of their clinics but more generally in their professional and personal lives. Within their clinics, wise practitioners bring all their clinical knowledge and skills to bear on their clinical judgements for particular clients. They recognise clients as experts in their own illness experiences, and negotiate treatment and management plans with them. They also collaborate with practitioners from other disciplines and refer clients as required so that they can receive the most appropriate care.

Wise actions are also called for in the broad contexts of the practitioner role and the role of a particular discipline in the wider health system. Health practitioners have responsibilities to engage with the world beyond their clinics in order to question dominant paradigms and taken-for-granted assumptions about the way our health system, and more broadly, society work. Health care systems in developed countries are facing a number of challenges that test their ability to deliver effective, efficient, and responsive services. These challenges are well documented and include increasing demand for services (Sibbald, Laurant, \& Scott, 2006), growing prevalence of chronic disease (Queensland Health, 2012), escalating service costs (Bosley \& Dale, 2008), diminishing workforce availability (Miers, 2010), and changing community expectations (Lewy, 2010). Responding to these challenges is a part of the lifelong learning and professional development of the virtuous practitioner.

\subsection{Love}

In popular culture in Australia, love is closely linked with romance and physical passion, and this is clearly distinctly inappropriate in the professional working environment. There are classifications which help understand the many different ways charity/love is expressed in society:

- Eros represents passionate yearning, sexual passion, and romantic love.

- Philia encapsulates brotherly love, friendship, loyalty to community and family.

- Agape stands for charitable, selfless love that is non-judgemental, and is given and asks for nothing in return (Halpin, 2009).

- Ludus is playful love and can be expressed through flirting and teasing.

- Pragma is mature, long standing love and refers to the deep understanding and tolerance that develops between, for example, long-committed couples.

- Philautia refers to love of self and this can be of two types, narcissism and 
healthy self-regard (Krznaric, 2014).

In the healing professions, we argue that therapeutic efficacy can be enhanced when practitioners develop agape. A relationship between practitioner and client that unselfconsciously incorporates this affect enhances the same trust, caring and commitment that underpins all successful relationships. Why would learning experiences that inculcate them in students not then be valuable additions to curricula in health sciences?

The concept of love is both complex and important and to introduce it into curricula and student learning requires serious consideration as it is easily misinterpreted. A more accessible and professionally acceptable term for this virtue in the practice context may be empathy. It is both necessary and appropriate to teach students about professional empathy, the boundaries of social responsibility, and the need for a development strategy for self-care. Caring and love are embraced in the concept of professional empathy. As Egnew (2005: 259) reports:

The role of the physician-healer is to establish connexional relationships with his or her patients and guide them in the reworking of their life narratives to create meaning in and transcend their suffering. Even though it is the patient who must find the meaning that transcends his or her suffering, the physician can catalyse this process by sensitively attending to and engaging the patient in dialogue regarding the patient's suffering.

Empathy is a concept cognate to love that is often enlisted in discussions of the supra-technical accomplishments of practitioners, but fails to convey the depth of the healing bond between practitioner and client that these categories of love might build. We argue that being able to identify at an emotional level with a patient-not simply feeling for them but feeling with them-enhances the quality of care provided to patients.

We do not question that empathy plays an important part in healing. What we suggest is that a practitioner who possesses the capacity to feel and convey agape will find empathy a more accessible tool than one who does not. This paper explores pedagogical ways that enable students to develop wisdom and love and apply them in clinical settings, while at the same time honouring the ethical principle of the boundary that circumscribes a practitioner's work and relationship with their clients. Demonstrating love, a dimension of the therapeutic relationship beyond a professional concern for, and empathy with, a patient's condition, while observing this boundary, can be a challenge for students and therefore requires thoughtful pedagogical approaches in allied health curricula.

\section{Practitioner Capabilities for Virtuous Practice}

The overarching remit of clinical practice is caring-doing whatever is within the practitioner's scope of practice to provide health care for clients while respecting their individual experience of their illness and treatment preferences. Caring involves dealing respectfully with clients' family and friends and with other members of the health care team, and advocating for their clients within 
the health service. It requires relational skills, reflexivity, and ethical decision-making. According to McEldowney \& Connor (2011) practicing caring is putting the perspectives of clients ahead of those of service values, and that this is a moral imperative for all practitioners. Virtuous practitioners require relational skills and the capacity for reflexivity and ethical decision-making. Integration of these skills is sometimes called phronesis (practice wisdom) and this is where practice extends beyond the practical into a deeper, more layered approach to professional practice (Baker et al., 2013; Saugstad, 2005).

\subsection{Relational Skills}

All health care interactions are potentially emotionally charged. Caring for patients involves engaging with patients' emotions, but emotional engagement must be paced and controlled. Health practitioners are called on to manage their own emotional reactions to their clients' conditions. They are also well aware that the outcomes of their clinical decisions can directly affect their clients' safety and wellbeing. Consequently, the nature of the relationship between client and practitioner and the nature of the decisions that they have to negotiate can cause a level of stress that is unique to clinical practice and calls for a correspondingly unique high level or emotional capability (Grace \& Orrock, 2015). An example of this is the emotional capabilities described for physiotherapists working in acute care settings (Smith, Higgs, \& Ellis, 2008). These include awareness of the effect that practitioners' emotions have on decision-making capacity, and the capacity to deal with problematic emotions when making the difficult decisions required for client management. Examples include a practitioner overcoming their distress at a patient's unreasonable behaviour towards them, or feeling inadequate to influence a family's healthcare decisions while knowing that the patient's health will suffer.

\subsection{Reflexivity}

Reflexivity in clinical practice involves 'reflection in and on actions in the practice context' (McEldowney \& Connor, 2011: 344). It goes beyond a practitioner's reflecting on past and current events and awareness of their own emotional responses to those events: reflexivity also involves awareness of the consequences of their actions on others, and awareness of how others see them and react to them. In the clinical environment, this means not only gauging clients' responses to their actions, but also being aware of the influence those responses can have on the therapeutic outcome of the treatment.

\subsection{Ethical Decision Making}

In any clinical encounter, numerous decisions are made which must accord with the standards of professional conduct expected of all professionals. These decisions include the diagnostic and treatment approach to be taken, the suitability of the patient for treatment by the practitioner, the need for referral, the strength 
of the evidence supporting the treatment, and the adequacy of the skill set of the practitioner (Grace \& Orrock, 2015). The practice of a virtuous practitioner conforms to professional codes of conduct, such as those set out by the Australian Health Practitioner Regulation Agency (Physiotherapy Board of Australia, 2014), and that clearly outline expectations and boundaries for professional practice.

\section{Implications for Allied Health Education}

Virtuous practitioners embody the practice of care. They have the relational competence to know how to draw on love in practice, the competence to be a reflexive practitioner that enables them as to understand actions and consequences in clinical environments, and the wisdom to apply technical competence within the ethical boundaries of clinical practice and to understand social and professional responsibility.

Sleeth (2010) reminded us that love is the healing principle in treatment, but there are challenges. Allied health student practitioners may feel cautious, uncertain or confused about what it actually means in a professional environment to bring love and wisdom to a therapeutic encounter. They may feel a number of social and personal constraints, and concerns about perceptions of their professionalism, when it comes to developing the aspect of professionalism that is about the 'whole person' and that involves more than the person's physical condition. These concerns mean that they might:

- lack confidence and/or communication skills,

- worry about projecting personal beliefs,

- fear/shy away from intrusion into personal lives,

- feel out of their depth/comfort zone,

- have no method for addressing these needs,

- see the emotional side of illness as a 'no-go' area,

However, student practitioners need to be taught to overcome these fears and uncertainties because they need to 'create safe contexts so that clients can reveal what is important to them' (McEldowney \& Connor, 2011: 345). To develop the skills of a virtuous practitioner practical strategies that develop student awareness of their boundaries, responsibilities and caring in a professional relationship, and which extend beyond technically competent diagnosis and treatment need to be integrated in curriculum design. Generic skills, like relational skills, are often taken for granted and undervalued when compared with highly technical advances in health care (Duke, 2005).

The process of learning relational skills or 'skills of involvement' depends on the availability of 'built in reflexive opportunities' (Duke, 2005: 47). Effective pedagogic strategies for cultivating virtues in clinical practice could incorporate a stream over a three year curriculum with teaching tools that initiate reflective development processes in students and utilise the debriefing component of clinic practicums into supervisor-led student-active self-development programs. While 
we recognise that such a teaching stream could require upskilling of teachers/supervisors, the benefit for practitioners and students would be considerable as they learn how to embrace and integrate the qualities of love and wisdom effectively and professionally within their practices. Key pedagogical strategies for cultivating good relational skills, reflexivity, and ethical decision-making in students include critical reflection and dialogic encounters, and these can be integrated in debriefing sessions and Grand Rounds.

\subsection{Critical Reflection}

Self-understanding and professional identity development are continually evolving processes (Fitzmaurice, 2013; McEldowney \& Connor, 2011). Critical reflection forms an essential part of health practitioner teaching and learning for its potential for cultivating reflexivity as part of clinical routine (Mezirow, 1997). It enables practitioners to use conscious thought processes to question and revise their own beliefs and behaviours and to understand diverse opinions and behaviours. Students can be encouraged to enter into a critical self-dialogue where they repeatedly evaluate their thoughts in relation to a particular context and in this way can develop insights into their own thoughts and behaviours (Forneris, 2004). Critical reflection activities include workshops and small group discussions, reflective journaling, in-depth reflective essays on ethical vignettes, reflective reports on client consultations, and self-assessment learning contracts. Reflective learning tasks can be embedded in regularly-used activities to help students learn how to integrate virtues into their clinical practice. Suitable activities include role plays, scenario-based assessment tasks, ePortfolios, case studies and vivas, observed structured clinical examinations, and observations in a clinical setting.

\subsection{Dialogic Encounters}

Dialogic encounters (Bakhtin, 1981) are opportunities for co-learning between participants. Discourse is 'constantly engaged with, and informed by, other voices' (Taylor \& Sutton, 2016: 190), all of which are equally entitled to be heard. Learning evolves throughout the encounter as participants contribute to, process, and respond to the inputs of their dialogic partners and new perspectives develop. Curricular space can be dedicated to such dialogic encounters as simulated and actual clinical practice and debates in the classroom, either online or face to face, where students can be encouraged to think out loud in a supportive learning environment. Audio recordings of dialogical encounters which capture the voices of clients and practitioners in the ethical decision-making process can be made available for discussion.

\subsection{Debriefing}

Of particular use in preparing future health practitioners are debriefing sessions after clinic practicums. At this critical time, students are keen to review their 
performance, reflect on their emotional responses to the therapeutic encounter, hear others' suggestions, and to receive support. These debriefing sessions could shift into a more deliberate examination of the nature of the therapeutic encounter, one that places equal emphasis on treatment and deconstruction of the nature of the practitioner-client relationship. In this session students could be asked difficult questions like:

- What, if anything, did you find challenging in your clinic session?

- Did anything challenge your knowledge and skills?

- Did you acquire new knowledge?

- What, if anything, pushed you out of your comfort zone?

- What did you learn from that?

\subsection{Grand Rounds}

Grand Rounds is a good example of a teaching technique that draws together many aspects of the client-practitioner experience. In one version of Grand Rounds, students select a case from their clinical practice, and present the case to their peers and teachers. The case presentation could include presenting symptoms, physical and other examination results, and a teaching point-an aspect of the case the student found challenging. Grand Rounds is traditionally used to discuss differential diagnoses, an essential part of health professional education, but can also be an opportunity to explore the emotional components of clinical practice in a supportive environment. Grand Rounds can be a 'safe place' for review and collegial conversation and can be used to develop emotional maturity through critical reflection, research and critical dialogue with peers and supervisors. After traditional questions like, What are your differential diagnoses for this case? What was your rationale for ruling them in or out? have been discussed, open questions like, Can you identify one key question that arose from this case? How did you go about answering this question? and What did you learn from the case? can promote critical reflection and dialogue about the more intangible elements that transform the practitioner's role in the therapeutic relationship from that of an efficient technician to one of healer.

An example from an undergraduate osteopathy training program illustrates the effectiveness of the Grand Rounds setting. The above questions were given to the 2016 cohort of fourth and fifth year osteopathic students. Many of their Grand Rounds presentations were focused discussions about differential diagnoses, but some students chose to present cases that prompted their reflection on such topics as shared decision making, dealing with a malingering patient, the moral appropriateness of continuing to treat a patient who showed no signs of improvement and the challenges of treatment dependency, how to motivate clients to make lifestyle changes, and what practitioners need to understand in order to provide the best quality care to members of the transgender community. These dialogic encounters work to build the capability for critical reflection in students and this underpins development of the virtues of wisdom and love. 
The pedagogical strategies discussed in this paper are limited to allied health students. Future research could explore these strategies, and others, in medical and nursing education. Future research could also evaluate the effectiveness of these strategies in developing virtuous practitioners and on the quality of health care provided to patients.

\section{Conclusion}

There is a clear responsibility in allied health program design to develop in neophyte practitioners the tools needed to become competent health professionals. A significant, integral and less often articulated aspect of this professional competence is the practice of virtues. This paper presents pedagogical strategies that can help students understand the importance of practicing virtuously and that operationalise this concept need to be embedded in allied health curricula. Opportunities for students to cultivate relational skills, reflexivity and ethical decision-making in the curriculum are required. Critical reflection in and on role plays, scenario-based assessment tasks, ePortfolios, studies and vivas; dialogic encounters through simulated and actual clinical practice and debates in the classroom; debriefing after clinical practice; and Grand Rounds can all be used to cultivate virtues in allied health students.

\section{References}

Baker, M., Beale, A., Hammersley, L., Lloyd, K., Semple, A., \& White, K. (2013). Ethical Practice in Learning through Participation: Showcasing and Evaluating the PACE Ethical Practice Module. Asia Pacific Journal of Cooperative Education, 14, 195-207.

Bakhtin, M. (1981). The Dialogic Imagination (C. E. M. Holquist, Trans.). Austin: University of Texis Press.

Barnett, R. (1997). Higher Education: A Critical Business. Buckingham: Open University Press.

Bosley, S., \& Dale, J. (2008). Healthcare Assistants in General Practice: Practical and Conceptual Issues of Skill-Mix Change. British Journal of General Practice, 58, 118-124. https://doi.org/10.3399/bjgp08X277032

Duke, K. (2005). A Century of CAM in New Zealand: A Struggle for Recognition. Complementary Therapies in Clinical Practice, 11, 11-16.

Egnew, T. (2005). The Meaning of Healing: Transcending Suffering. The Annals of Family Medicine, 3, 255-262. https://doi.org/10.1370/afm.313

Fitzmaurice, M. (2013). Constructing Professional Identity as a New Academic: A Moral Endeavour. Studies in Higher Education, 38, 613-622.

https://doi.org/10.1080/03075079.2011.594501

Forneris, S. (2004). Exploring the Attributes of Criting Thinking: A Conceptual Basis. International Journal of Nursing Scholarship, 1 (Article 9). Retrieved from http://www.bepress.com/ijnes/vol1/iss1/art9 https://doi.org/10.2202/1548-923X.1026

Grace, S., \& Orrock, P. (2015). Criticality in Osteopathic Medicine. In M. Davies \& R. Barnett (Eds.), The Palgrave Handbook of Critical Thinking (pp. 475-490). New York: Palgrave Macmillan. https://doi.org/10.1057/9781137378057_28 
Halpern, J. (2003). What Is Clinical Empathy? Journal of General Internal Medicine, 18, 670-674. https://doi.org/10.1046/j.1525-1497.2003.21017.x

Halpin, D. (2009). Pedagogy and Romantic Love. Pedagogy, Culture \& Society, 17, 89-102. https://doi.org/10.1080/14681360902742910

Jones, M., \& Rivett, D. (2004). Clinical Reasoning for Manual Therapists. Edinburgh: Butterworth Heinemann.

Krieger, D. (1992). The Therapeutic Touch: How to Use Your Hands to Help or Heal. New York, NY: Fireside.

Krznaric, R. (2014). Empathy. Why It Matters and How to Get It. London: Rider.

Lewy, L. (2010). The Complexities of Interprofessional Learning/Working: Has the Agenda Lost It's Way? Health Education Journal, 69, 4-12. https://doi.org/10.1177/0017896910363299

Marcum, J. (2011). The Role of Prudent Love in the Practice of Clinical Medicine. Journal of Evaluation in Clinical Practice, 17, 877-882. https://doi.org/10.1111/j.1365-2753.2011.01719.x

McEldowney, R., \& Connor, M. (2011). Cultural Safety as an Ethic of Care: A Praxiological Process. Journal of Transcultural Nursing, 22, 342-349. https://doi.org/10.1177/1043659611414139

Mezirow, J. (1997). Transformative Learning: Theory to Practice. New Directions for Adult and Continuing Education, 74, 5-12. https://doi.org/10.1002/ace.7401

Miers, M. (2010). Professional Boundaries and Interprofessional Working. In K. Pollard, J. Thomas, \& M. Miers (Eds.), Understanding Interprofessional Working in Health and Social Care (pp. 105-120). Hampshire: Palgrave Macmillan.

Morad, M., Merrick, J., \& Ventegodt, S. (2004). Clinical Holistic Medicine: Classic Art of Hearling or the Therapeutic Touch. The Scientific World Journal, 4, 143-147.

Physiotherapy Board of Australia (2014). Code of Conduct. http://www.physiotherapyboard.gov.au/Codes-Guidelines/Code-of-conduct.aspx

Queensland Health (2012). Strategic Plan 2012-2016. https://www.health.qld.gov.au/_data/assets/pdf_file/0017/441620/strategic-plan12-16update13.pdf

Saugstad, T. (2005). Aristotle's Contribution to Scholastic and Non-Scholastic Learning Theories. Pedagogy, Culture \& Society, 13, 347-366. https://doi.org/10.1080/14681360500200233

Schön, D. (1987). Educating the Reflective Practitioner. San Francisco, CA: Jossey-Bass.

Sibbald, B., Laurant, M., \& Scott, T. (2006). Changing Task Profiles. In A. Saltman, A. Rico, \& W. Boerma (Eds.), Primary Care in the Driver's Seat? Organisational Reform in European Primary Care (pp. 149-164). Berkshire: Open University Press.

Sleeth, D. (2010). Integral Love: The Role of Love in Clinical Practice as a Rite of Passage. Journal of Humanistic Psychology, 50, 471-494. https://doi.org/10.1177/0022167810361970

Smith, M., Higgs, J., \& Ellis, E. (2008). Factors Influencing Clinical Decision Making. In J. Higgs, M. Jones, S. Loftus, \& N. Christensen (Eds.), Clinical Reasoning in the Health Professions (pp. 89-100). Sydney: Butterworth-Heinemann.

Taylor, P., \& Sutton, P. (2016). Hearing the Marginalised Voices. In J. Higgs, \& F. Trede (Eds.), Professional Practice Marginalia (pp. 189-196). Rotterdam: Sense. https://doi.org/10.1007/978-94-6300-600-2_22 